\title{
Evaluating impact of demerit points system on speeding behavior of drivers
}

\author{
Arif Mehmood
}

Received: 10 January 2009 / Accepted: 2 February 2010 / Published online: 2 March 2010

(C) The Author(s) 2010. This article is published with open access at Springerlink.com

\begin{abstract}
Objective The objective of this research was to evaluate the immediate impact of the demerit points system on speeding behavior of drivers in Al Ain. Al Ain is the fourth largest city in the United Arab Emirates, located about $120 \mathrm{Km}$ from Dubai.

Methods The spot speed data of randomly selected vehicles using speed guns was collected from three major arterial urban roads. The data was collected three months before and three months after the implementation of the demerit points system. The free flow conditions were considered during the data collection. The data was analyzed using SPSS program.

Results and Conclusions The results revealed that the demerit points system has statistically no significant impact on the speeding behavior of drivers in Al Ain. One of the plausible reasons for insignificance affect of the demerit point system could be the lack of effective traffic monitoring system. This study recommends that to influence the drivers' behavior an effective traffic monitoring system should be provided to achieve the desired outcomes of introducing tougher laws such as demerit point system. The study also recommends to collect more data to investigate the changes in the speeding behavior of drivers.
\end{abstract}

Keywords Driver behavior · Demerit points · Speeding · Road safety

\footnotetext{
A. Mehmood $(\bowtie)$

Department of Transport,

PO Box 20, Abu Dhabi, United Arab Emirates

e-mail: arif.mehmood@dot.abudhabi.ae
}

\section{Introduction}

It is widely recognized that speeding is the most frequent traffic law violation, and is responsible for many severe road crashes all over the world [1, 5, 25, 31]. Speeding is reported as dangerous as drunk driving: [17] reported that the risk of a road crash increases exponentially as speed or blood alcohol concentration increases. Excessive or inappropriate speed is reported as a major cause of about onethird of fatal road crashes in many countries [25, 32]. Indeed, reducing speeding could decrease the occurrence of road crashes, and subsequent severity of the road crashes $[25,29]$. Among many other researchers, Nilsson [23] and Elvik et al. [9] tested the association between speed and road safety using a power model on different types of roads, and concluded that speed and road safety have a strong statistical association. For example, a $10 \%$ reduction in the mean speed of traffic could result in an approximately $37.8 \%$ reduction in the number of fatalities $[9,23]$.

However, establishing an environment for a continuous reduction in the speeding violations has been a challenge in many countries. General examples of various measures implemented in different countries to control the speeding problem include: 1) strengthening law enforcement by introducing tougher penalties such as heavy fines or demerit points system for speed limit violations and/or increasing the traffic monitoring by regular police patrol and/or using automated devices (speed cameras), 2) raising awareness level of drivers about the road safety to motivate drivers to comply with the speed limits [8, 11, 18], 3) changing road attributes like providing humps at "Black Spot" locations or narrowing lane widths [21], and 4) introducing Advanced Driver Assistance Systems such as Intelligent Speed Adaption [15, 20]. 
The ultimate objective of these various measures mentioned above is to positively change the behavior of drives and eventually improve the road safety by minimizing road crashes. It is an important task to formally evaluate impact of measures aimed at improving road safety. The purpose of this study is to evaluate impact of the demerit points system on speeding behavior of drivers in $\mathrm{Al}$ Ain. $\mathrm{Al}$ Ain is the fourth largest city in the United Arab Emirates which has a population of nearly 500,000 and is located about $120 \mathrm{Km}$ from Dubai.

The demerit points system has been implemented in many countries including Australia, Belgium, Italy, Ireland, Canada, France, Germany, Japan, New Zealand, Norway, the United Kingdom and the US [13, 16, 19, 24, 28, 33]. The researchers in these countries have unanimously endorsed the effectiveness of the demerit points system in influencing the driver behavior to adhere to the traffic regulation and some of the studies reported the subsequent reduction of up to $20 \%$ in roadway crash fatalities. While some researchers argued that the overall effect of the demerit points system on road safety remains controversial, emphasizing that influence of the demerit points system was not sustained for more than 6 months $[4,6,7,12]$, however, Vaa and Glad [30] reported that on the long run when demerit points accumulates, the number of subsequent violations tends to decline.

While most of reported studies evaluated the impact of demerit points systems on final outcomes such as the reduction of road crashes and/or reduction of crash severity. This study attempts to evaluate the impact of the demerit points systems on the immediate targets such as reduction of speeding behaviors of drivers in Al Ain. In Al Ain, traffic violations and aggressive driving are a common phenomenon. The most common causes of road crashes reported by the Al Ain Traffic Police include speeding, sudden lane change, violation of traffic regulations, and tailgating [22]. According to the Traffic Police officials the culture of speeding is so deeply rooted that in general, drivers perceive speeding violation as a normal offense. The road crash statistics obtained from the Ministry of Interior for the period (2005-2008) revealed that speeding contributed to over $40 \%$ of severe road crashes in $\mathrm{Al}$ Ain. In addition, according to the officials at the $\mathrm{Al}$ Ain traffic police department a recent increase in the number of road crash fatalities was mostly due to increase in the severity of road crashes resulting from speeding. Evidence shows that a substantial number of road crashes resulted in the instant deaths of passengers and drivers [22]. One plausible major cause of these severe incidents in Al Ain was undoubtedly speeding. It is, therefore, clear that the problem of speeding is sizeable and constitutes a big concern to traffic authorities in $\mathrm{Al}$ Ain and the UAE.

On March 01, 2008 a new traffic law of demerit points system was introduced in the United Arab Emirate. With this new law if a driver accumulates 24 points in a year, his/ her driving license will be confiscated for six months and his or her vehicle for a month. Furthermore, if a driver accumulates 24 black points twice in one year, his/her driving license will be cancelled, his or her vehicle will be confiscated for three months and he or she will be required to take a driving test one year after the date he/she accumulated the maximum points. The aim of introducing the demerit points system was to reduce the traffic law violations. The demerit points system is considered as more severe sanction than fines, thus it could be more effective in controlling the traffic law violations [2]. Ostvik [26] in Norway investigated driver's attitude towards punishments, and reported that $76 \%$ of drivers agreed that only severe fines coupled with the loss of driving license could be more effective to modify the drivers' behaviors.

\section{Methodology}

\subsection{Data collection}

The spot speed data of randomly selected SUVs and Sedan vehicles were collected using hand-held speed guns. Bener et al. [3] compared the pattern of road crash severities involving SUVs and Sedan vehicles in Al Ain. The study reported that magnitude of injuries involving SUVs was higher than Sedan vehicles, and the major reason reported for higher degree of severity was excessive speeding [3]. In this study the reason for collecting speed data of SUVs and Sedan vehicle was to explore the difference between behavior of SUVs and Sedan drivers. The data was collected from three main arterial urban roads in Al Ain over a period of $1.5 \mathrm{~h}$. The reason for choosing duration of $1.5 \mathrm{~h}$ was to collect speed data of a substantial number of vehicles. Table 1 shows some characteristics of roads and observed traffic volume for each road.

The data was collected three months before and three months after the implementation of the demerit points system during the same hours on same days. The locations for recording spot speeds were carefully selected to consider the free flow conditions and to avoid the influence of road attributes such as intersections or access/exit points

Table 1 Characteristics of roads and observed traffic volume

\begin{tabular}{lccrc}
\hline & $\begin{array}{l}\text { Speed Limit } \\
(\mathrm{Km} / \mathrm{h})\end{array}$ & Number of lanes & $\begin{array}{l}\text { Before } \\
(\mathrm{N})\end{array}$ & \multicolumn{1}{l}{$\begin{array}{l}\text { After } \\
(\mathrm{N})\end{array}$} \\
\hline Road 1 & 60 & 3 & 471 & 387 \\
Road 2 & 80 & 3 & 1008 & 921 \\
Road 3 & 80 & 3 & 795 & 556 \\
\hline
\end{tabular}

$\mathrm{N}$ represents the number of vehicles observed during $1.5 \mathrm{hrs}$ 
on the speed choice behavior of drivers. During the data collection the traffic on roads under observations was lower than the capacity of $5100 \mathrm{vph}$ (i.e. $1700 \times 3$ lanes). This reflects drivers were able to choose their own speed.

\subsection{Data analysis and results}

The approach applied to analyze the data was "Independent sample t-test using SPSS". In this approach the difference in mean speeds of before and after samples was investigated. The details of this approach can be found in [14]. The spot speed data for before and after samples were coded in SPSS. A factor variable with a value of 1 and 2 was used to distinguish before and after speed, factor $=1$ refers to before and factor $=2$ represents speed after the implementation of demerit points systems. The null hypothesis was that the means of before and after samples are not significantly different, and the alternate hypothesis was the means is significantly different.

The Tables 2, 3 and 4 present the results of the "Independent sample t-test in SPSS". Before and after mean speed of Sedan and SUVs vehicles were analyzed separately as well as together to investigate the difference in drivers of Sedan and SUVs vehicles. However, results revealed no difference between SUVs and Sedan drivers. For the purpose of simplification the results of SUVs and Sedan vehicles are combined. These results are presented in Tables 2, 3 and 4. In these tables, the "Group Statistics", the Levene's test for equality of variances, and t-test for equality of means are presented. The group statistics include sample sizes (n), means, standard deviations, and standard error mean. The Levene's test checks the homogeneity of the samples (i.e. the two variances are significantly different or not) and the t-test presents the significance of difference in means [14].

As shown in the Tables 2, 3 and 4 under the Group Statistics, it is found that there is not much difference in the before and after mean speeds of vehicles, and the results of the Levene's test indicate that the two variances are not significantly different; that is, the two variances are approximately equal. The values under "Sig." in the Levene's test are greater than the critical value of 0.05 . Finally, based on the results of Levene's test the top rows in the t-test for Equality of Means indicate the significance values for all cases is greater than 0.05 . This implies that there is no significant difference in the mean speeds of vehicles before and after the demerit points system.

In addition to above analysis, spot speed data for before and after samples were divided into various classes and then the frequency distributions of these classes were compared separately for SUVs, Sedan, and both types of vehicles. The comparisons of these frequency distributions for both vehicles are shown in the Figs. 1, 2 and 3. The






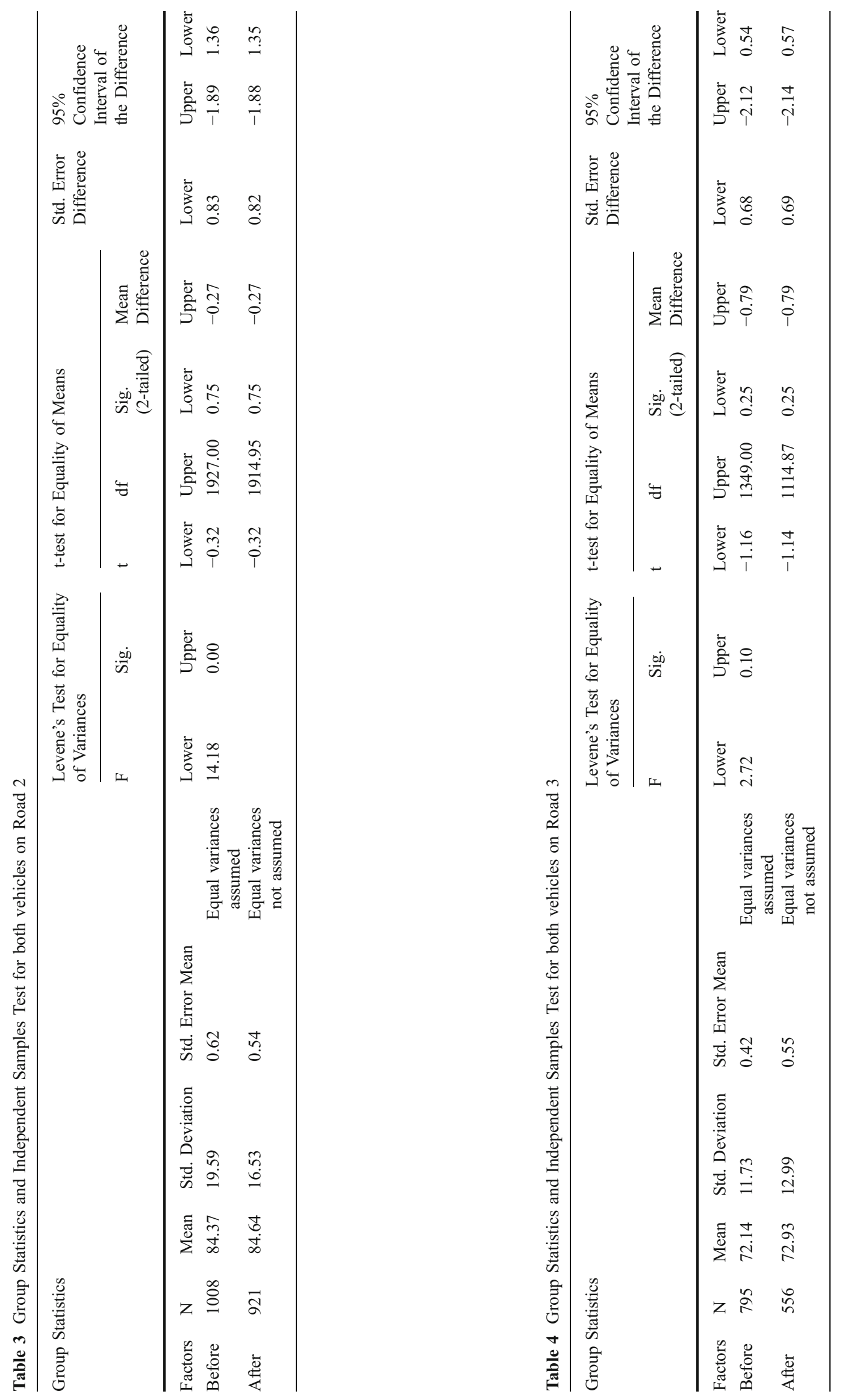

슬 Springer 


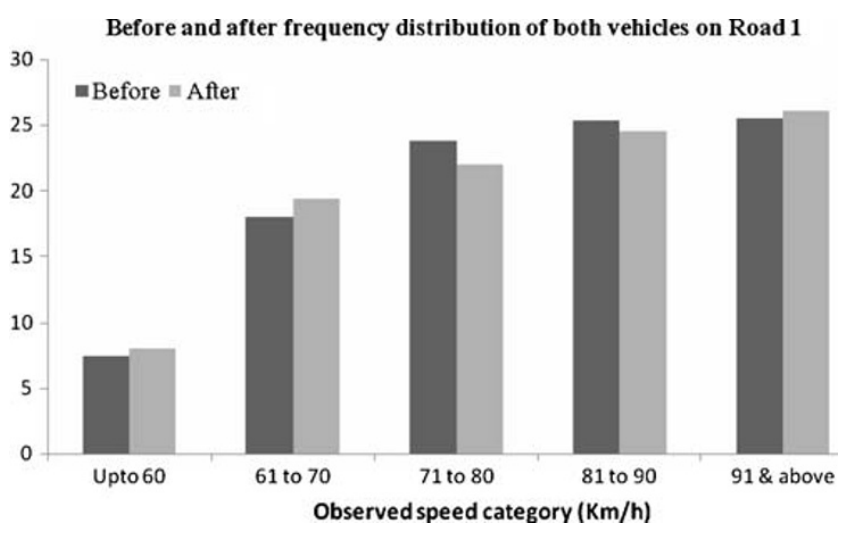

Fig. 1 Comparison between before and after frequency distribution of both vehicles on Road 1 for various observed speed categories

visual inspection of these figures also indicates that there is no significant difference in before and after speed distributions. However, as shown in the Fig. 2, it appears that the frequency of vehicles for higher speed categories has slightly (i.e. 5\%) increased after the demerit points system. Furthermore, it appears that for most of the higher speed categories there is not much considerable reduction in speed after the demerit points system.

\section{Conclusions and recommendations}

This article focused on evaluating immediate impact of the demerit points system on speeding behavior of drivers in Al Ain. The spot speed data three months before and three months after introducing the demerit point system was collected from three arterial urban roads. The analysis revealed that the demerit points system has no significant effect on the speeding behavior of drivers. As results indicated that there was no significant difference before and after the enforcement of the demerit points system. Further comparison of the frequency distribution of various classes of spot speed

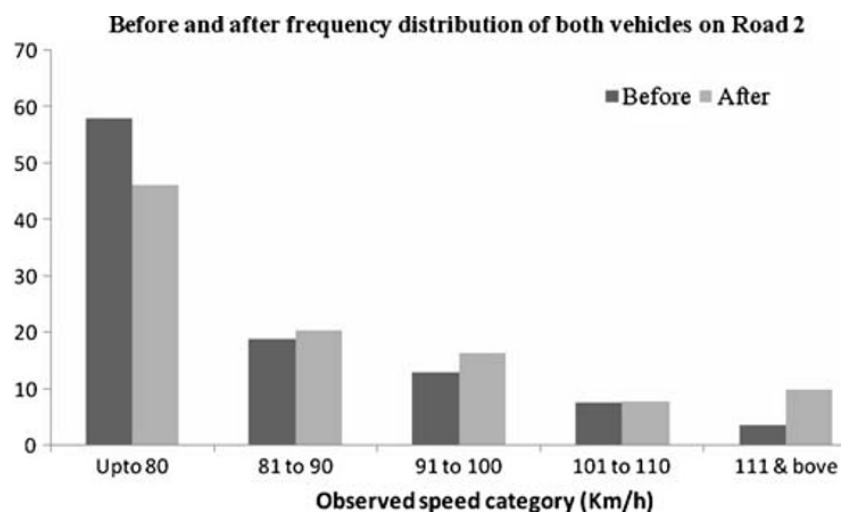

Fig. 2 Comparison between before and after frequency distribution of both vehicles on Road 2 for various observed speed categories

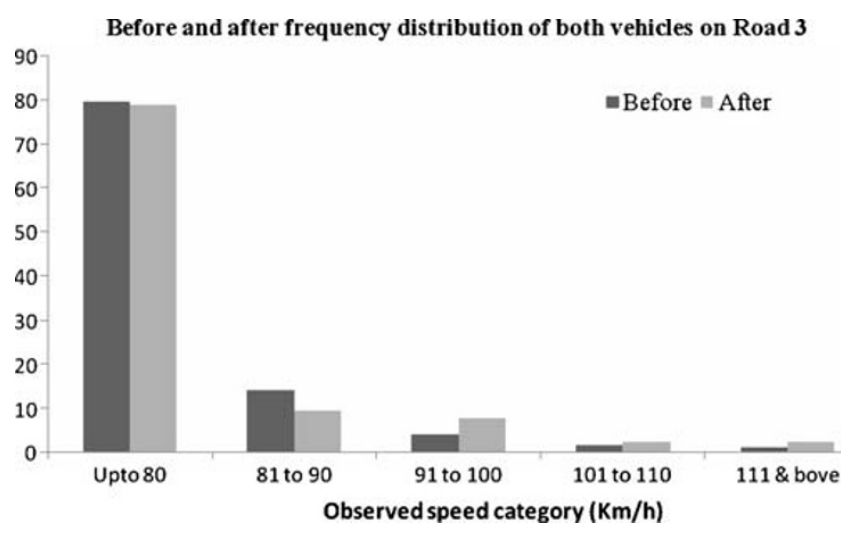

Fig. 3 Comparison between before and after frequency distribution of both vehicles on Road 3 for various observed speed categories

data also showed no significant difference. The study also found that there is no difference in speeding behavior of drivers of SUVs or Sedan vehicles before and after the introduction of the new law.

Even though the demerit points system has been found effective to influence the driver behavior elsewhere, however, the findings of this study are not consistent with studies, for example [13, 16, 19, 24, 28, 33] which support the effectiveness of demerit points system. One plausible reason for the inconsistency of findings could be the lack of sustained and visible enforcement in Al Ain. Currently, the installation of fixed speed detecting cameras is in progress. It is expected that in the near future speed cameras will be functional that may influence drivers to change their speeding behavior. This supports the argument reported by Peden et al. [27] that experience in many countries has shown that demerit points system may not have effective outcomes unless effectively supported by visible enforcement. Further Elvik (2001b) and others [10] supported that "highly visible police or camera activity can bring about lasting changes in road user behavior and, as a consequence, changes in road users' attitudes which reinforce these behavioral changes".

During the data collection it was noted that there were no monitoring systems such as automated devices (fixed or mobile) or regular police patrol in place on the roads where data was collected. This implies that the speeding behavior of drivers observed in this study was assessed without the influence of traffic monitoring systems. It is recommend that in future this study should be extended to include more roads equipped with the speed cameras to verify the effect of the demerit points system on speeding behaviors of drivers in Al Ain.

Based on the results of this study, it is reasonable to propose that the introduction of the demerit points system could be more effective with the support of an efficient traffic monitoring system and also with the publicity through media campaigns through regional $\mathrm{TV}$, radio, and 
newspapers [32]. This study recommends that to influence the drivers' behavior an effective traffic monitoring system should be provided to achieve the desired outcomes of introducing tougher laws such as demerit point system.

Open Access This article is distributed under the terms of the Creative Commons Attribution Noncommercial License which permits any noncommercial use, distribution, and reproduction in any medium, provided the original author(s) and source are credited.

\section{References}

1. Aberg L (1997) The role of perceived risk detection. In: Rothengatter I, Carbonell E (eds) Proceedings of the International Conference on Traffic and Transport Psychology, Valencia (1996). Amsterdam: Elsevier.

2. ACTS (2001) 2001 seat belt summit: policy options for increasing seat belt use in the United States in 2001 and beyond. Automotive Coalition for Traffic Safety, Arlington

3. Bener A, Ghaffar A, Azad A, Sankarran-Kutty M, Toth F, Lovasz G (2006) The impact of four-wheel drivers on road traffic disability and deaths compared to passenger cars. JCPSP 16(4):257-260

4. Butler JS, Burke JP, Healy DG, Stephens MM, McManus F, McCormack D, O'Byrne JM, Poynton AR (2006) Trends in RTA related spinal injuries: the post penalty points era. Ir J Med Sci 175(1):20-23

5. Carcary WB, Power KG, Murray FA (2001) The new driver project: changing driving beliefs, attitudes and self-reported driving behavior amongst young drivers through classroombased pre and post driving test interventions. Scottish executive central research unit. http://www.scotland.gov.uk/cru/kd01/blue/ newdriver-00.asp

6. Donnelly M, Murray P, Cleary S (2005) Changes in trauma service workload since the introduction of the penalty points system. Ir Med J 98:53-54

7. Diamantopoulou K, Cameron M, Dyte D (1997) The relationship between demerit points accrual and crash involvement, Monash University Accident Research Centre. Report no.116. http://www. monash.edu.au/muarc/reports/muarc116.html

8. Elliott B (1993) Road safety mass media campaigns: a meta analysis prepared by Barry Elliott for the Federal Office of Road Safety Road safety mass media campaigns. Rep. No. CR 118, Federal Office of Road Safety

9. Elvik R, Christensen P, Amundsen A, (2004) Speed and road accidents: an evaluation of the Power Model. report 740/2004. Institute of Transport Economics, Oslo

10. ETSC (1999) Police enforcement strategies to reduce traffic casualties in Europe, European Transport Safety Council, ISBN: 90-76024-06-05. http://www.etsc.be/oldsite/strategies.pdf

11. Gregersen NP, Linderoth B (1997) Framtid på väg, KFB \& VTI Forskning/Research 20, VTI, Linköping S. In Swedish, reported in "Speed Management" reported by OECD 2006, Transport Research Center, European Conference of Ministers of Transport

12. Healy DG, Connolly P, Stephens MM, O’Byrne JM, McManus F, McCormack D (2004) Speed and spinal injuries. Injury 35 (9):908-912

13. Hussain OT, Nayyar MS, Brady FA, Beirne JC, Stassen LF (2006) Speeding and maxillofacial injuries: impact of the introduction of penalty points for speeding offences. Br J Oral Maxillofac Surg 44 (1):15-19
14. Howell DC (2006) Fundamental Statistics for the Behavioral Sciences Wadsworth Publishing, ISBN: 0495099007

15. Jamson S, Carsten O, Chorlton K, Fowkes M (2006) Intelligent speed adoption. Literature review and scoping study. Leeds: University of Leeds, MIRA Ltd and Transport for London

16. Jonah BA, Boase P, Dawson N (2004) Occupant restraint use in Canada. Journal of Safety 35(2):223-229

17. Kloeden CN, McLean AJ, Moore VM, Ponte G (1997) Travelling speed and the risk of crash involvement. Volume 1: findings. Report CR 172. Federal Office of Road Safety FORS, Canberra

18. Lawton R, Parker D, Manstead ASR, Stradling SG (1997) The role of affect in predicting social behaviours: the case of road traffic violations. J Appl Soc Psychol 27:1258-1276

19. Lenehan B, Street J, Barry K, Mullan G (2005) Immediate impact of 'penalty points legislation' on acute hospital trauma services. Injury 36(8):912-916

20. Marchau VAWJ, Van der Heijden RECM, Molin EJE (2005) Desirability of advanced driver assistance from road safety perspective: the case of ISA. Saf Sci 43:11-27

21. Mountain LJ, Hirst WM, Maher MJ (2005) Are speed enforcement cameras more effective than other speed management measures? The impact of speed management measures on 30 mph roads. Accident Anal Prev 37(4):742-754

22. Ministry of Interior (2005 to 2008) Road Crash Statistics, United Arab Emirates

23. Nilsson G (2004) Traffic safety dimensions and the power model to describe the effect of speed on safety. Lund Bulletin 221. Lund Institute of Technology, Lund

24. National Highway Traffic Safety Administration (2002) National survey of speeding and unsafe driving attitudes and behavior. Washington, DC. Available from http://www.nhtsa.dot.gov/people/ injury/research/speed volII finding/SpeedVolumeIIFindingsFinal.pdf

25. OECD (2006) Speed management. European Conference of Ministers of Transport. Organization for Economic Co-operation and Development

26. Ostvik E (1989) Road traffic law enforcement-Conceptual framework for public surveillance Techniques, Report ISBN-827133-646-0, TOI, Institute of Transport Economics, Oslo

27. Peden M, Scurfield R, Sleet D (2004) World report on road traffic injury prevention. World Health Organisation (WHO). Available from URL: http://www.who.int/bookorders/MDIbookPDF/Book/ 11500572.pdf

28. Poli de Figueiredo LF, Rasslan S, Bruscagin V, Cruz R, Rocha e Silva M (2001) Increases in fines and driver licence withdrawal have effectively reduced immediate deaths from trauma on Brazilian roads: first-year report on the new traffic code. Injury 32(2):91-94

29. Taylor MC, Lynam DA, Baruya A (2000) The effects of drivers' speed on the frequency of road accidents, TRL Report 421, prepared for the Road Safety Division, DETR

30. Vaa T, Glad A (1995) reported in "Traffic enforcement in Europe: effects, measures, needs and future, Final report of the ESCAPE consortium, The "Escape" Project. http://ec.europa.eu/transport/ roadsafety_library/publications/escape_final_report.pdf

31. Wegmand F, Aarts L (2006) Advancing sustainable safety: national road safety outlook for 2005-2020. SWOV Institute for Road Safety Research, The Netherlands

32. Zaal D (1994) Traffic law enforcement: a review of the literature. Monsah University Crash Research Centre. Report No. 53. Canberra

33. Zambon F, Fedeli U, Milan G, Brocco S, Marchesan M, Cinquetti S, Spolaore P (2008) Sustainability of the effects of the demerit points system on seat belt use: a region-wide before-and-after bservational study in Italy. Accident Anal Prev 40:231-237 